Bangladesh J. Pl. Breed. Genet., 25(2): 25-32, 2012

\title{
GENETIC VARIABILITY, HERITABILITY AND CORRELATION IN STEM AMARANTH (Amaranthus tricolor)
}

\author{
A. U. Ahammed, M. M. Rahman and M. A. K. Mian ${ }^{1}$ \\ Department of Horticulture \\ Bangabandhu Sheikh Mujibur Rahman Agricultural University \\ Gazipur 1706, Bangladesh
}

\begin{abstract}
Genetic variability, heritability and correlation analysis were done for yield and its component characters in twenty two (22) diverse genotypes of stem amaranth. The highest PCV (87.85\%) and GCV (81.67\%) were observed for primary branches per plant while the lowest PCV $(10.28 \%)$ was found in plant height and the lowest GCV (7.51\%) was found in leaf width. Heritability estimates in broad sense were higher for leaf weight per plant $(91.10 \%)$ followed by leaves per plant $(86.83 \%)$, primary branches per plant $(86.42 \%)$, stem weight per plant $(82.56 \%)$ and yield per hectare $(78.70 \%)$. Leaf weight per plant, stem weight per plant and yield per hectare exhibited high value of heritability $(91.10 \%, 82.56 \%$ and $78.70 \%)$ along with high genetic advance $(49.38 \%, 134.12 \%$ and $56.00 \%)$, respectively. Leaves per plant, stem diameter, stem weight per plant, leaf weight per plant and plant height exhibited highly significant positive correlation with yield per hectare both at genotypic and phenotypic level. Selection based on these traits would give better response for the improvement in marketable yield in stem amaranth.
\end{abstract}

Key words: Stem amaranth (Amaranthus tricolor); GCV; PCV; heritability; genetic advance and correlation.

\section{INTRODUCTION}

Stem amaranth is a summer vegetable and popularly known as danta. It is a very fast growing crop with and extremely high yield potential. The amaranth is considered to be native of India (Nath, 1976). The centre of diversity for amaranths are Central and South America, India, South East Africa (Grubben, 1977). A wide variation is reported to exist with in each species for growth habit, disease resistant, taste and quality, thus offering considerable scope for future breeding program. Different types of genotypes are grown by the farmers in our country (Rashid, 1999). Significant variations were present among the lines for plant height, number of leaves, stem girth and yield (Hamid et al., 1989).

Presence of variability in a base population is very important for any improvement program. Identification of genotypes with high variability and heritability for desirable characters in a pre-requisite in the development of varieties with high yield potential Yield is a complex character controlled by many factors. Therefore, selection for desirable types should not only be restricted to yield alone but other components related to yield should also be considered (Varalaksmi and Reddy, 1997).

\footnotetext{
${ }^{1}$ Department of Genetics and Plant Breeding, Bangabandhu Sheikh Mujibur Rahman Agricultural University, Gazipur 1706, Bangladesh.
} 
Bangladesh is very rich in amaranth germplasm but no systematic work has been undertaken to standardize the existing local germplasm and new varieties. Hence, the present study was undertaken to find out and establish suitable selection criteria for higher yield through study of variability, heritability and correlation between yield and its components in amaranth.

\section{MATERIALS AND METHODS}

Twenty two genotypes of stem amaranth were grown in a Randomized Complete Block Design (RCBD) with three replications at the experimental field laboratory, Department of Horticulture, Bangabandhu Sheikh Mujibur Rahman Agricultural University (BSMRAU), Gazipur, Bangladesh during April 2007 to July 2007. The experimental materials consisted of 22 genotypes of stem amaranth collected from PGRC, BARI, Gazipur, East-West Seed Co. (Lal Teer Seed Ltd.), BRAC and from different districts of Bangladesh. The plot size was $1.5 \mathrm{~m} \times 1.5 \mathrm{~m}$. The seed drilling was done between rows about $30 \mathrm{~cm}$ apart and seeds were sown continuously in the rows. Seedlings were thinned maintaining a spacing of $30 \mathrm{~cm} \times 10 \mathrm{~cm}$ after 15 days of sowing. Intercultural operations were done following Rashid (1999). Yield contributing data have been recording from the mean of ten harvested plants selected randomly from each genotype in each replication. The crop was harvested when started flowering. Data were recorded during harvesting time on ten characters namely plant height $(\mathrm{cm})$, leaves per plant, leaf length $(\mathrm{cm})$, leaf width $(\mathrm{cm})$, stem diameter $(\mathrm{mm})$, primary branches per plant, leaf weight per plant (g), stem weight (g), leaf : stem ratio and total yield (t/ha).

Genotypic and phenotypic variance and Broad sense heritability were estimated according Johnson et al. (1955). Genotypic and phenotypic co-efficient of variation were estimated according to Burton (1952). Expected genetic advance (GA) was calculated according Johnson et al. (1955). Genetic advance in percent of mean was estimated by using the formula suggested by Comstock and Robinson (1952). Correlation co-efficient was worked out according to Panse and Sukhatme (1967).

\section{RESULTS AND DISCUSSION}

\section{Genetic Variability, Heritability and Genetic Advance:}

The estimates of genotypic variance $(\mathrm{GV})$, phenotypic variance $(\mathrm{PV})$, genotypic co-efficient of variation (GCV), phenotypic co-efficient of variation (PCV), broad sense heritability $\left(\mathrm{h}_{\mathrm{b}}{ }_{\mathrm{b}}\right)$, genetic advance (GA) and genetic advance in percent of mean (GAPM) for different characters are presented in Table 2. The analysis of variance showed a wide range of variation and significant differences for all the characters (Table 1). In variability study, the phenotypic co-efficient of variation (PCV) was higher than the genotypic co-efficient of variation (GCV) for all the characters which is in general agreement with the findings of Sharma et al., (1997). The coefficients of variation at phenotypic (PCV) and genotypic (GCV) level were high for primary branches per plant, leaf weight per plant and stem weight per plant and medium to low for other characters. The differences in the magnitude of PCV and GCV were for those characters indicating more influence of environment in their governance while PCV and GCV were close together (less differences) for those characters indicating less influence of environment in their governance and selection for those characters would be effective (Rana et al., 2005).The highest PCV (87.85\%) and GCV (81.67\%) were observed for primary branches per plant while the lowest PCV (10.28\%) was found in plant height and the lowest GCV (7.51\%) was found in leaf width. 
The highest heritability $(91.10 \%)$ was observed for leaf weight per plant followed by leaves per plant $(86.83 \%)$ and the lowest heritability $(29.44 \%)$ was observed in leaf width. The highest genetic advance (134.12\%) was observed for stem weight per plant and the lowest (0.09\%) was observed for leaf-stem ratio. Rahman et al. (2005) obtained the highest heritability for leaf weight per plant $(92.79 \%)$ followed by plant height $(77.33 \%)$.Moderate to low estimates of broad sense heritability indicates that improvement through selection would be limited (Rana et al., 2005).

Robinson et al. (1949) arbitrarily categorized the estimates of heritability as low (5-10\%), medium (10-30\%) and high (30\% and above). Following this classification, the heritability estimates obtained for all the characters were quite high except leaf width in the present investigation.

Table 1. Analyses of variance for different characters of stem amaranth genotypes.

\begin{tabular}{lccc}
\hline Characters & Block & Genotypes & Error \\
\hline Degrees of freedom & 2 & 21 & 42 \\
Plant height (cm) & 203.874 & $371.219^{* *}$ & 71.883 \\
Leaves/plant & 0.563 & $51.444^{* *}$ & 2.475 \\
Leaf length (cm) & 0.088 & $12.595^{* *}$ & 3.238 \\
Leaf width $(\mathrm{cm})$ & 4.939 & $3.580^{*}$ & 1.590 \\
Stem diameter (mm) & 0.063 & $19.188^{* *}$ & 4.656 \\
Primary branches/plant & 0.903 & $9.465^{* *}$ & 0.471 \\
Leaf weight/plant (g) & 26.696 & $1953.682^{* *}$ & 61.637 \\
Stem weight/plant (g) & 1757.532 & $16486^{* *}$ & 1084.388 \\
Leaf : stem ratio & 0.002 & $0.009^{* *}$ & 0.001 \\
Total yield (t/ha) & 20.427 & $1828.254^{* *}$ & 82.364 \\
\hline
\end{tabular}

* indicates significant at $5 \%$ level of significance.

** indicates significant at $1 \%$ level of significance.

Table 2. Estimates of mean, range, genotypic variance, phenotypic variance, genotypic and phenotypic co-efficient of variation, heritability and genetic advance in stem amaranth

\begin{tabular}{|c|c|c|c|c|c|c|c|c|c|}
\hline Characters & Mean & Range & GV & PV & $\begin{array}{c}\text { GCV } \\
(\%)\end{array}$ & $\begin{array}{c}\text { PCV } \\
(\%)\end{array}$ & $\begin{array}{l}\mathrm{h}^{2}{ }_{\mathrm{b}} \\
(\%)\end{array}$ & GA & $\begin{array}{c}\text { GAPM } \\
\text { (as \%of } \\
\text { mean) }\end{array}$ \\
\hline Plant height $(\mathrm{cm})$ & 127.50 & $101.3-145.0$ & 99.78 & 171.66 & 7.84 & 10.28 & 58.13 & 15.69 & 12.31 \\
\hline Leaves/plant & 18.89 & $11.11-30.00$ & 16.32 & 18.80 & 21.39 & 22.96 & 86.83 & 7.76 & 41.06 \\
\hline Leaf length $(\mathrm{cm})$ & 20.14 & $17.00-23.78$ & 3.12 & 6.36 & 8.77 & 12.52 & 49.06 & 2.55 & 12.65 \\
\hline Leaf width $(\mathrm{cm})$ & 10.85 & $9.33-13.67$ & 0.66 & 2.25 & 7.51 & 13.84 & 29.44 & 0.91 & 8.39 \\
\hline Stem diameter $(\mathrm{mm})$ & 20.90 & $16.71-27.63$ & 4.84 & 9.50 & 10.53 & 14.75 & 50.99 & 3.24 & 15.49 \\
\hline Primary branches /plant & 2.12 & $0.00-5.10$ & 3.00 & 3.47 & 81.67 & 87.85 & 86.42 & 3.32 & 156.41 \\
\hline Leaf weight/ plant (g) & 92.06 & $53.51-168.83$ & 630.68 & 692.32 & 27.28 & 28.58 & 91.10 & 49.38 & 53.63 \\
\hline Stem weight /plant (g) & 308.30 & $167.0-465.8$ & 5134.19 & 6218.58 & 23.24 & 25.58 & 82.56 & 134.1 & 43.50 \\
\hline Leaf: stem ratio & 0.30 & $0.23-0.43$ & 0.003 & 0.004 & 17.04 & 19.98 & 72.73 & 0.09 & 29.94 \\
\hline Total yield (t/ha) & 148.20 & $84.50-226.9$ & 939.06 & 1193.15 & 20.68 & 23.31 & 78.70 & 56.00 & 37.79 \\
\hline
\end{tabular}

Genetic advance expressed as percentage of mean was high for primary branches per plant, leaf weight per plant; stem weight per plant and leaves per plant and moderate to low for other characters .Relationship of heritability and genetic advance also give an idea about the type of gene action. Both additive and non additive gene actions were found predominant for all the characters which suggest that the simple selection methods alone will not be effective hence hybridization followed by selection would be a better choice for amaranth improvement (Rana et al., 2005). High heritability with high genetic advance could be considered reliable tools for selection (Chaudhury and Sharma, 2003). 
From the study it was also found that leaf weight per plant, stem weight per plant and yield per hectare exhibited high value of heritability along with high genetic advance suggesting that these characters can be improved by phenotypic selection. Similar results were also obtained by Varalakshmi and Reddy (1997).

In general, the characters exhibiting high heritability with high genetic advance are genetically controlled by additive genes (Panse, 1957) and can be improved upon through mass selection, family selection or any other modified selection procedures whereas, the characters with low heritability and low genetic advance can be improved through hybridization (Liang and Walter, 1968). While the characters which exhibit high heritability with moderate or low genetic advance can be improved by inter mating the superior genotypes of the segregating population developed from multiple crosses and the desirable genes can be accumulated in the lines.

\section{CORRELATION COEFFICIENTS}

Genotypic and phenotypic correlation coefficients between yield and its components are presented in Table 3. In most of the cases genotypic correlation coefficients were higher than the phenotypic correlation coefficients which indicate apparent association may be largely due to genetic reason (strong coupling linkage). The difference between genotypic and phenotypic correlation was in general low indicating the environmental effect, did not have much influence on these characters. Ahmed et al. (1978) also reported that magnitude of genotypic correlations were higher than their respective phenotypic correlations. In few cases, however, phenotypic correlation coefficients were higher than their genotypic correlation coefficients suggesting that both environmental and genotypic correlation in these cases act in the same direction and finally maximize their expression at phenotypic level. Results of genotypic and phenotypic correlation coefficient of yield and its contributing characters of different genotypes of stem amaranth have been discussed character wise as follows:

\section{Plant height}

Plant height was found to observe significantly positive relationship with yield per hectare both at genotypic and phenotypic level (Table 3). Plant height also showed significant positive correlation with stem weight per plant both at genotypic and phenotypic level and positive significant correlation with leaf weight per plant at genotypic level and insignificant positive correlation with leaf weight per plant at phenotypic level. Plant height also showed insignificant positive correlation with leaves per plant, leaf length, primary branches per plant and leaf width where as plant height showed insignificant negative correlation with leaf: stem ratio and stem diameter both at genotypic and phenotypic level. The above results indicate that increasing plant height caused the plant to increase stem weight per plant and leaf weight per plant. The above findings were in agreement with Rahman et al. (2000) and Varalakshmi and Reddy (1997).

\section{Leaves per plant}

Leaves per plant showed highly significant positive correlation with yield per hectare, leaves weight per plant and stem weight per plant both at genotypic and phenotypic level where as stem diameter showed significant positive correlation with leaves per plant at genotypic level and non significant positive correlation with leaves per plant at phenotypic level (Table 3). Leaves per plant also showed non significant positive correlation with leaf length, leaf width and leaf: stem ratio both at genotypic and 
phenotypic level and non significant negative correlation with primary branches per plant at genotypic level and significant positive correlation with phenotypic level. It appeared from the results that increasing number of leaves caused the plant to increase yield. Mohideen and Subramanian (1974) reported that leaves per plant showed positive correlation with yield which was in agreement with present findings.

\section{Leaf length}

Leaf length showed non significant positive correlation with yield per hectare, stem diameter, primary branches per plant and stem weight per plant both at genotypic and phenotypic level and leaf width at genotypic level (Table 3). Leaf length had highly significant positive relation with both leaf: stem ratio and leaf weight at genotypic level and significant positive relationship with leaf: stem ratio and leaf weight at phenotypic level. It also showed significant positive relationship with leaf width at phenotypic level. Mohideen and Subramanian (1974) reported that leaf length showed significant association with yield which was in agreement with the present findings.

\section{Leaf width}

Leaf width showed highly significant positive relationship with yield per hectare, leaf weight per plant, stem weight per plant and stem diameter and significant positive relationship with leaf: stem ratio at genotypic level. It showed significant positive relationship with leaf weight per plant and non significant positive relationship with yield per hectare, stem weight per plant, stem diameter and leaf: stem ratio at phenotypic level (Table 3). It also showed non significant positive relationship with primary branches per plant both at genotypic and phenotypic level. Varalaksmi and Reddy (1997) and Mohideen and Muthukrishnan (1979) reported that leaf width showed highly significant positive relationship with yield of greens which was in agreement with the present findings.

\section{Stem diameter}

Stem diameter was found to display highly significant positive relationship with yield per hectare, leaf weight per plant and stem weight per plant both at genotypic and phenotypic level (Table 3). Stem diameter showed non significant negative association with primary branches both at genotypic and phenotypic level. It also showed non significant positive association with leaf: stem ratio at genotypic level and nonsignificant negative association with leaf: stem ratio at phenotypic level. It appeared from the results that increasing stem diameter also increased yield of amaranth. Rahman et al. (2005) reported that stem diameter showed highly significant positive correlation with yield of greens which was in agreement with the present investigation.

\section{Primary branches per plant}

Primary branches per plant were found to observe non significant positive correlation with yield per hectare, stem weight per plant, leaf weight per plant and leaf: stem ratio both at genotypic and phenotypic level (Table 3). It appeared from the results that increasing primary branches per plant had no contribution for increased stem yield. Varalaksmi and Reddy (1997) reported that primary branches per plant showed non significant correlation with yield of greens which was in agreement with the present findings. 


\section{Stem weight per plant}

Stem weight per plant showed highly significant positive correlation with yield per hectare and leaf weight per plant both at genotypic and phenotypic level (Table 3). It also showed negative non significant correlation with leaf: stem ratio both at genotypic and phenotypic level. It appeared from the results that increasing stem weight per plant increased the yield of amaranth. Similar results were obtained by Mohideen and Muthukrishnan (1979) and Varalaksmi and Reddy (1997).

\section{Leaf weight per plant}

Leaf weight per plant was found to observe the highly significant positive relationship with yield per hectare and non-significant positive correlation with leaf: stem ratio both at genotypic and phenotypic level (Table 3). It appeared from the results that increasing leaf weight per plant also increased yield of amaranth. Similar results were obtained by Mohideen and Muthukrishnan (1979) and Varalaksmi and Reddy (1997).

\section{Leaf : stem ratio}

Leaf stem ratio showed non significant negative correlation with yield per hectare both at genotypic and phenotypic level (Table 3). Varalaksmi and Reddy (1997) and Campbell and Abbott (1982) reported that yield was negatively correlated with leaf: stem ratio indicating that a higher yielder should always have a low leaf: stem ratio which was in agreement with the present findings.

Table 3. Genotypic and phenotypic correlations among different characters of stem amaranth genotypes

\begin{tabular}{|c|c|c|c|c|c|c|c|c|c|c|}
\hline \multicolumn{2}{|c|}{ Characters } & LP & LL & LW & SD & $\mathrm{PB}$ & SWP & LWP & LSR & TYH \\
\hline \multirow[t]{2}{*}{$\mathrm{PH}$} & $r_{g}$ & 0.418 & 0.304 & 0.109 & -0.158 & 0.314 & $0.518^{*}$ & $0.459 *$ & $\begin{array}{l}-0.097 \\
\end{array}$ & $0.520 *$ \\
\hline & $r_{p}$ & 0.393 & 0.192 & 0.067 & -0.005 & 0.216 & $0.425^{*}$ & 0.357 & -0.153 & $0.482 *$ \\
\hline \multirow[t]{2}{*}{ LP } & $r_{g}$ & & 0.316 & 0.197 & $0.456 *$ & -0.011 & $0.695 * *$ & $0.798 * *$ & 0.245 & $0.769 * *$ \\
\hline & $r_{p}$ & & 0.260 & 0.099 & 0.398 & 0.006 & $0.626^{* *}$ & $0.736^{* *}$ & 0.179 & $0.684 * *$ \\
\hline \multirow[t]{2}{*}{ LL } & $r_{g}$ & & & 0.359 & 0.135 & 0.336 & 0.202 & $0.635^{* *}$ & $0.812 * *$ & 0.348 \\
\hline & $r_{p}$ & & & $0.433^{*}$ & 0.183 & 0.275 & 0.197 & $0.530 *$ & $0.530^{*}$ & 0.299 \\
\hline \multirow[t]{2}{*}{ LW } & $r_{g}$ & & & & $0.728 * *$ & 0.322 & $0.564 * *$ & $0.836 * *$ & $0.452 *$ & $0.649 * *$ \\
\hline & $r_{p}$ & & & & 0.308 & 0.266 & 0.370 & $0.448^{*}$ & 0.150 & 0.401 \\
\hline \multirow[t]{2}{*}{ SD } & $r_{g}$ & & & & & -0.206 & $0.739 * *$ & $0.704 * *$ & 0.097 & $0.767 * *$ \\
\hline & $r_{p}$ & & & & & -0.089 & $0.617 * *$ & $0.572 * *$ & -0.110 & $0.640 * *$ \\
\hline \multirow[t]{2}{*}{ PB } & $r_{g}$ & & & & & & 0.002 & 0.255 & 0.373 & 0.069 \\
\hline & $r_{p}$ & & & & & & 0.049 & 0.249 & 0.271 & 0.084 \\
\hline \multirow[t]{2}{*}{ SWP } & $r_{g}$ & & & & & & & $0.837 * *$ & -0.175 & $0.999 * *$ \\
\hline & $r_{p}$ & & & & & & & $0.748 * *$ & -0.281 & $0.898 * *$ \\
\hline \multirow[t]{2}{*}{ LWP } & $r_{g}$ & & & & & & & & 0.377 & $0.921 * *$ \\
\hline & $r_{p}$ & & & & & & & & 0.375 & $0.842 * *$ \\
\hline \multirow[t]{2}{*}{ LSR } & $r_{g}$ & & & & & & & & & -0.015 \\
\hline & $r_{p}$ & & & & & & & & & -0.061 \\
\hline
\end{tabular}

* indicates significant at $5 \%$ level of significance.

** indicates significant at $1 \%$ level of significance.

$\mathrm{PH}=$ Plant height, $\mathrm{LP}=$ Leaves per plant, $\mathrm{LL}=$ Leaf length, $\mathrm{LW}=$ Leaf width, $\mathrm{SD}=\mathrm{Stem}$ diameter, $\mathrm{PB}=$ Primary branches per plant, $\mathrm{SWP}=$ Stem weight per plant, LWP=Leaf weight per plant, LSR=Leaf: stem ratio and TYH=Total yield (t/ha).

From the present study it was found that among the yield contributing characters plant height had significant positive correlation with yield per hectare both at genotypic and phenotypic level. Leaves per plant, stem diameter, stem weight per plant and leaf 
weight per plant had highly significant positive correlation with yield per hectare both at genotypic and phenotypic level. Results indicated that these characters have the major contribution towards the yield per hectare of stem amaranth. It also showed that yield per hectare is negatively correlated with leaf: stem ratio indicated that stem characters contributes more towards yield than leaf characters. Plant height was significantly and positively correlated with stem weight per plant both at genotypic and phenotypic level and it was also significantly and positively correlated with leaf weight per plant at genotypic level and non significantly and positively correlated with leaves per plant at phenotypic level indicating that yield increased with increasing plant height, stem weight per plant and leaf weight per plant. It is therefore indicated that importance may be given to select plants with comparatively longer stem, increased stem diameter and more weight of stem per plant.

\section{REFERENCES}

Ahmed, Z., J. C. Sharma, R. P. Katiyar and R. S. Bhatia. 1978. Path analysis of productivity in wheat. Indian Journal of Genetics and Plant Breeding. 38(3): 299303.

Burton, G. W. 1952. Quantitative inheritance in grasses. $6^{\text {th }}$ Int. Grass Land cong. 1: 277- 283.

Campbell, T. A. and J. A. Abbott. 1982. Field evaluation of vegetable amaranth (Amaranthus spp.). Horticultural Science. 17(3): 407-409.

Chaudhury, D. K. and R. R. Sharma. 2003. Genetic variability, correlation and path analysis for green pod yield and its components in garden pea. Indian Journal of Horticulture. 60(3): 251-256.

Comstock, R. E. and H. F. Robinson. 1952. Genetic parameters, their estimation and significance. Proc. $6^{\text {th }}$ Int. Grassland Cong. 1: 284-291. 1: 277-283.

Grubben, G. J. H. 1977. Tropical vegetables and their genetic resources, Ed. G. D. Tindall and J. T. Williams, Rome, pp. 91-100. In: C. R. Muthukrishnan and I. Irulappan. Amaranthus.p. 671.

Bose, T. K. and M. G. Som (eds.). 1986. Vegetable crops in India. Naya Prokash, Calcutta six.

Hamid, M. M., N. U. Ahmed and S. M. M. Hossain. 1989. Performance of some local and exotic germplasm of amaranth. Agricultural Science Digest. 9:202-204.

Johnson, H. W., H. E. Robinson and R. E. Comstock. 1955. Estimates of genetic variability and environmental variability in soybean. Agron. J. 47: 314-318.

Liang, G. H. L. and T. L. Walter. 1968. Heritability estimates and gene effect for agronomic traits in grain Sorghum.Crop Science. 8: 77-80.

Mohideen, M. K. and C. R. Muthukrishnan. 1979. Studies on correlation, multiple regression and path analysis as related to yield of vegetable amaranth (Amaranthus tricolor). Proc. $2^{\text {nd }}$ Amaranth conference, Rome, Rodale Press. Inc.pp. 74-78.

Mohideen, M. K. and A. S. Subramanian. 1974. Correlation studies in Amaranthus. South Indian Hort. 22: 132-133. In: C.R. Muthukrishnan and I. Irulappan. Amaranthus. p. 678. T.K. Bose and M.G. Som (eds.) 1986. Vegetable crops in India. Naya Prokash, Calcutta six.

Nath, P. 1976. Vegetables for the Tropical Region, ICAR, New Delhi. In: C.R. Muthukrishnan and I. Irulappan. Amaranthus. p. 670. T.K. Bose and M.G. Som (eds.) 1986. Vegetable crops in India. Naya Prokash, Calcutta six. 
Panse, V. G. 1957. Genetics of quantitative characters in relation to plant breeding. Indian Journal of Genetics and Plant Breeding. 17: 318-328.

Panse, V. G. and P. V. Sukhatme. 1967. Statistical method for Agricultural workers. $2^{\text {nd }}$ Ed. Indian council of Agricultural research, New Delhi. p. 381.

Rahman, M. M., M. G. Rasul, M.S. Islam, N. Sultana and M. A. Hossain. 2000. Genetic divergence in Chilli (Capsicum anum L.). Bangladesh Journal of Plant Breeding and Genetics. 12(2): 07-11.

Rahman, M. M., A. K. M. A. Islam and S.I. Hossain. 2005. Genetic variability, correlation and path analysis in amaranth (Amaranthus tricolor L.). Bangladesh Journal of Life Science. 17(1): 129-134.

Rana, J. C., S. K. Yadab, S. Mandal and Sangeeta Yadab. 2005. Genetic divergence and interrelationship analysis in grain amaranth (Amaranthus hypochondriacus) germplasm. Indian Journal of Genetics. 65(2): 99-102.

Rashid, M. M. 1999. "Shabjee Biggan” (in Bengali). $2^{\text {nd }}$ Edn. Rashid publishing house, Dhaka 1206. pp. 488-491.

Robinson, H. F., R. E. Comstock and B. H. Harvey. 1949. Estimation of heritability and the degree of dominance in corn. Agronomy Journal. 42: 553-559

Sharma, D. K., D. R. Choudhury and V. K. Choudhury. 1997. Genetic variability, heritability and genetic advance for yield and its contributing traits in pea. Indian Journal of Horticulture. 54(3): 242-246.

Varalakshmi, B. and P. V. V. Reddy. 1997. Variability, heritability and correlation studies in vegetable amaranth. Indian Journal of Horticulture. 54(2): 167-170. 